\title{
Individual quality persists between years: individuals retain body condition from one winter to the next in Teal
}

\author{
Matthieu Guillemain • Andy J. Green • \\ Géraldine Simon • Michel Gauthier-Clerc
}

\begin{abstract}
Few studies have considered how body condition changes over time in individual birds, and most of these concerned long-lived breeding birds. We used a large database of Common Teal Anas crecca ringed and recaptured while wintering in the Camargue to study interannual persistence in wing length and body condition. Winter body condition may be a major determinant of survival during that season, and may further be related to breeding success. Indices of condition were compared for individual Teal between the moments of ringing and of recapture the following winter, analyzing each sex and age class (adult or juvenile) separately. Wing length was highly repeatable between years, though some limited annual variation was also recorded in adult males. Using scaled mass index as an index of body condition, we observed that condition at ringing was the strongest predictor of body condition at recapture for males and juvenile females, although inter- and intra-annual variation was also significant in most cases. The value of the slope for the relationship between individual body condition indices at ringing and recapture did not differ from 1 for males and
\end{abstract}

\footnotetext{
M. Guillemain ( $\square)$

CNERA Avifaune Migratrice, Office National de la Chasse et de la Faune Sauvage, La Tour du Valat, Le Sambuc, 13200 Arles, France

e-mail: matthieu.guillemain@oncfs.gouv.fr
}

\author{
A. J. Green \\ Department of Wetland Ecology, Estación Biológica de Doñana- \\ CSIC, Avda. Américo Vespucio s/n, 41092 Sevilla, Spain \\ G. Simon · M. Gauthier-Clerc \\ Centre de Recherche de la Tour du Valat, Le Sambuc, \\ 13200 Arles, France
}

for adults, whereas, for juvenile females, the slope was significantly greater than 1 , indicating that individual differences in condition became more exaggerated over time. When analyses were repeated using crude body mass instead of a condition index, results were generally similar. Birds recaptured the following winter had a greater body condition at ringing that those that were not recaptured, supporting the hypothesis of a link between winter body condition and return probability. Our results demonstrate the importance of a head start in Teal, given persistent effects of obtaining better condition in the first winter, and suggest specific age and sex effects. They also underline the value of condition indices as a long-term predictor of individual quality in birds, even during the non-breeding season and for such a relatively short-lived species.

Keywords Scaled mass index · Inter-annual changes · Body size $\cdot$ Fitness $\cdot$ Inter-annual persistence

\section{Zusammenfassung}

Individuelle Qualität bleibt von Jahr zu Jahr bestehen: Krickenten behalten ihre individuelle Körperkondition von einem Winter zum nächsten bei

Es gibt nur wenige Studien zu zeitlichen Veränderungen der Körperkondition von Vogelindividuen; die meisten von diesen Untersuchungen betreffen zudem langlebige Vogelarten zur Brutzeit. Anhand einer großen Datenmenge von Krickenten Anas crecca, die in ihrem Winterquartier in der Camargue beringt und wiedergefangen wurden, untersuchten wir die Persistenz von Flügellänge und Körperkondition von einem Jahr zum anderen. Die winterliche Körperkondition kann einen Hauptüberlebensfaktor zu dieser Jahreszeit darstellen und darüber hinaus mit dem Bruterfolg 
zusammenhängen. Es wurden Konditionsindizes für einzelne Krickenten zwischen dem Zeitpunkt der Beringung und dem Wiederfang im darauf folgenden Winter verglichen; dabei wurden Geschlechter und Altersklassen (adult oder juvenil) getrennt analysiert. Die Flügellänge war von einem Jahr zum anderen sehr gut reproduzierbar, obgleich bei den adulten Männchen auch eine gewisse jährliche Variation zu beobachten war. Unter Verwendung des Scaled Mass Index (SMI) als Maß der Körperkondition konnten wir feststellen, dass die Kondition bei der Beringung für Männchen und juvenile Weibchen die besten Voraussagen der Körperkondition beim Wiederfang erlaubte, obwohl die Variation innerhalb und zwischen den Jahren in den meisten Fällen ebenfalls signifikant war. Der Steigungswert für die Beziehung zwischen den individuellen Konditionsindizes bei Beringung und Wiederfang wich bei Männchen und Adulten nicht von $1 \mathrm{ab}$, für juvenile Weibchen hingegen war die Steigung beträchtlich größer als 1, was darauf hinweist, dass die individuellen Unterschiede in der Kondition im Laufe der Zeit zunahmen. Als die Analysen mit der Rohkörpermasse anstelle eines Konditionsindex wiederholt wurden, waren die Ergebnisse insgesamt ähnlich. Vögel, die im Folgewinter wiedergefangen wurden, hatten bei der Beringung eine bessere Körperkondition als solche, nicht wiedergefangen wurden, was auch die Hypothese eines Zusammenhanges zwischen winterlicher Körperkondition und der Rückkehrwahrscheinlichkeit stützt. Unsere Ergebnisse belegen, wie wichtig ein Konditionsvorsprung für die Krickente in Anbetracht der langfristigen Auswirkungen einer besseren Kondition im ersten Winter ist und deuten auf spezifische Alters- und Geschlechtseinflüsse hin. Außerdem unterstreichen sie den Nutzen von Konditionsindizes zur langfristigen Vorhersage individueller Qualität bei Vögeln, selbst außerhalb der Brutzeit und für solch eine relative kurzlebige Art.

\section{Introduction}

It is increasingly accepted that population dynamics are heavily influenced by the demographic heterogeneity among individuals, with some surviving better and/or producing more offspring annually than others, and hence playing a greater role in maintaining populations (e.g. Hauser et al. 2006; Gimenez and Choquet 2010). The consequences of inter-individual heterogeneity for population growth rate (or, conversely, extinction risk) are likely to differ depending on whether individual quality is conserved to some extent from year to year, i.e. if the 'better' individuals one year tend to be the same ones in future years (structured vs. unstructured heterogeneity; cf Kendall and Fox 2002, 2003; Robert et al. 2002, 2003; Cam et al. 2013).
Some longitudinal studies at the individual level (i.e. following the same individuals from year to year) have demonstrated that the most productive breeders tend to be the same over time (e.g. Evans 1979; Raveling 1981; Black et al. 2007; Blas et al. 2009), or the same individuals repeatedly show greater probability to survive until the next year (e.g. Barbraud and Weimerskirch 2005). Although persistence of individual quality has sometimes been demonstrated over the short term (2-3 years in Catry et al. 1999), such studies are typically conducted in long-lived species during the breeding season, when the same individuals likely come back year after year to the same breeding site (e.g. colony). In comparison, short-lived species are more difficult to study in this context and the persistence of their individual vital characteristics has consequently received far less attention.

Body condition indices can be more easily measured than breeding success or survival, and can act as a proxy for prediction of future individual survival and breeding success, i.e. fitness. Although the best way to index or estimate body condition has been intensely debated (Green 2001; Stevenson and Woods 2006; Peig and Green 2010; Labocha and Hayes 2012), individuals with a better condition index have been shown to survive better (e.g. Lindén et al. 1992; review in Johnson et al. 1992) and to produce more or larger offspring (e.g. Ankney and MacInness 1978; Krapu 1981; Ebbinge and Spaans 1995; Bowler 1996; Madsen and Shine 1999; Amat et al. 2001; Gladbach et al. 2010). Many studies have demonstrated how environmental conditions may lead average body condition of a population to vary over years (Chastel et al. 1995; Anteau and Afton 2009; Norte et al. 2009) or from one site to another (e.g. Hohman 1993; Ormerod and Tyler 1990; Peig and Green 2010). However, because it is difficult to repeatedly assess the body condition of the same individuals over years, very few studies have looked at persistence in body condition index from year to year, which may be masked by such environmental variation (e.g. Blums et al. 2005; Gladbach et al. 2010). Analyses of this type were generally conducted for birds during the breeding season (see, however, Hatch and Smith 2010).

Ducks (Anatidae) are among the species for which survival and breeding success have been shown to increase with body condition (Alisauskas and Ankney 1992; Blums and Clark 2004), but repeated body condition assessments of the same individuals through time have, again, mostly been performed on breeding birds, generally only females (e.g. Hepp and Kennamer 1993; Milonoff et al. 2002; Blums et al. 2005). Winter body condition is, however, also a parameter of great importance, likely to affect duck survival during that season specifically (e.g. Haramis et al. 1986; Conroy et al. 1989; Davis et al. 2011), and also possibly to affect subsequent breeding success in Common 
Teal Anas crecca (hereafter Teal) through carry-over effects (Guillemain et al. 2008), i.e. processes occurring during a given season that affect birds during a subsequent season. Persistent inter-individual difference in quality has been demonstrated among breeding duck populations (e.g. Blums et al. 2005), which should theoretically lead (through seasonal carry-over effects) to similar persistence from one winter to the next. However, there could also be life history trade-offs by which the most productive breeders are in poorer body condition the next winter, and vice versa (cost of reproduction; e.g. Nur 1984). The aim of the present study, using wintering Teal as a model species, is therefore to test whether the same individuals are able to maintain a better condition from one winter to the next. Beyond the simple example of the Teal, this study also aims at providing information in the context of structured versus unstructured heterogeneity among animal populations, i.e. whether differences between individuals are more likely to be fixed over time or, conversely, to fluctuate from one season to the next owing to environmental stochasticity.

We first test if wing length, often used as an index of structural size in birds (review in Rising and Somers 1989), shows inter-annual variation or, conversely, is repeatable between moulting events (e.g. De la Hera et al. 2009). We then test the repeatability between years for two measures of body condition, namely scaled mass index (SMI, body mass corrected for body size) and crude body mass, and assess the relative role of individual intrinsic features (i.e. body condition of that individual the previous year) compared to inter- and intra-annual (i.e. seasonal) environmental variation. After showing that the 'best' teal tend to be the same individuals over successive years, the third aim of this study was to analyze slopes to determine whether the potential differences in body condition between individuals become reduced or exaggerated over time on average (i.e. do the 'best' Teal of an annual catch become even better the next year?). Finally, we present a preliminary analysis of a link between body condition and survival of individual Teal, through the assessment of the potential relationship between body mass or body condition index and likelihood of recapture (hence, survival) from one year to the next.

\section{Methods}

Source of the data

A total of 59,187 Teal were ringed in Camargue, southern France $\left(43^{\circ} 30^{\prime} \mathrm{N}, 04^{\circ} 40^{\prime} \mathrm{E}\right)$ by researchers from the Tour $\mathrm{du}$ Valat biological station from the mid-1950s to the mid1970s. This yielded 20,123 live recaptures at the same spot, some individuals being recaptured several tens of times. Of these, 1,452 individuals were recaptured at least once after one or more years following their year of ringing (i.e. interannual recaptures), a 'year' or 'season' here being considered to be from 1 August year $x$ to 31 July year $x+1$. All birds were weighed to the nearest gram and their flattened wing length measured to the nearest $\mathrm{mm}$ at ringing and at each recapture event. In the present analysis, we only considered data collected at ringing and at first recapture the following year. Teal indeed are typical shortlived ducks, and the mean annual survival rate of generally around $50 \%$ (e.g. Devineau et al. 2010) leads to very few birds being recaptured more than one year after their initial ringing. Years with extreme cold spells in the Camargue (i.e. winters 1955-56, 1961-62 and 1963-64) were discarded (as both ringing and recapture years) because birds were in exceptionally poor body condition during and after such periods (see also Guillemain et al. 2005a). A total of 634 individuals ringed between 26 November 1956 and 22 January 1973 were hence considered in the present analysis (Table 1). Age of the individuals always refers to age determined at ringing, which was assessed by a combination of plumage and cloaca examination.

\section{Individual body size and body condition variables}

Individual body size was assessed by wing length, which was the only size measurement taken in this dataset. Body condition for each bird was first computed as its SMI following Peig and Green $(2009,2010)$ and using wing length as our measure of structural size. Residuals from an ordinary least squares regression of body mass against wing length are often used as a condition index, but such

Table 1 Number of Teal Anas crecca of each sex and age class ringed in Tour du Valat and recaptured at least once the following year

\begin{tabular}{lcrccr}
\hline $\begin{array}{l}\text { Ringing } \\
\text { year }\end{array}$ & $\begin{array}{l}\text { Adult } \\
\text { females }\end{array}$ & $\begin{array}{l}\text { Juvenile } \\
\text { females }\end{array}$ & $\begin{array}{l}\text { Adult } \\
\text { males }\end{array}$ & $\begin{array}{l}\text { Juvenile } \\
\text { males }\end{array}$ & Total \\
\hline 1956 & 14 & 48 & 24 & 57 & 143 \\
1957 & 11 & 125 & 49 & 74 & 259 \\
1958 & 10 & 40 & 31 & 14 & 95 \\
1959 & 3 & 7 & 9 & 2 & 21 \\
1964 & 5 & 2 & 15 & 5 & 27 \\
1965 & 5 & 3 & 16 & 6 & 30 \\
1966 & 2 & 1 & 10 & 4 & 17 \\
1967 & 3 & 3 & 2 & 5 & 13 \\
1968 & 0 & 5 & 5 & 4 & 14 \\
1969 & 1 & 1 & 5 & 2 & 9 \\
1970 & 0 & 0 & 3 & 1 & 4 \\
1971 & 0 & 0 & 1 & 0 & 1 \\
1972 & 0 & 0 & 1 & 0 & 1 \\
Total & 54 & 235 & 171 & 118 & 634 \\
\hline
\end{tabular}


residuals fail to correct for structural size in Teal (Green 2001), are poor predictors of the size of energy stores in ducks (Schamber et al. 2009), and are generally outperformed by the SMI (Peig and Green 2010; Bókony et al. 2012). Because there is equivalent random and uncorrected error in both the $\mathrm{X}$ (body size) and the $\mathrm{Y}$ terms (body mass), a standardized major axis (SMA) regression is used in the process of computing the SMI (Peig and Green 2009). We computed $b_{\mathrm{SMA}}$ of the population (the scaling exponent estimated by the SMA regression of body mass on wing length) from body mass and wing length measurements at ringing, using SMATR software (Warton et al. 2006; Arnold and Green 2007). This provided a $b_{\text {SMA }}$ value of 4.005 (95\% confidence interval 3.754-4.272) with an $r^{2}=0.315(P<0.0001)$. SMI was then separately calculated at ringing and at recapture for each individual (see Peig and Green 2009 for detailed methods, and Appendix 1 for details of current SMI calculations in Teal).

The use of one single body size variable is controversial, especially if this variable is wing length (e.g. Freeman and Jackson 1990; Flinks and Salewski 2012). Unfortunately, wing length is often the only measurement of body size taken during ringing operations, and this was the case here. It should be noted that, beyond possible observer errors in wing length measurements, one common problem in using wing length as a proxy for body size is that individuals from different subpopulations may have wings of different shapes (hence lengths) owing to different migration distances (e.g. Voelker 2001; O'Hara et al. 2006). Such a hypothetical link between wing length and migration distance was not supported by earlier analyses in Teal $(\mathrm{Gu}-$ illemain et al. 2009), suggesting that wing length may be a more valid proxy for body size at the population level in this species than in other ones. Furthermore, in another wintering population of Teal, Green et al. (2001) found that wing length and tarsus length (another measure frequently taken during ringing programmes) had similar correlations with body mass, suggesting that they are equally good measures of structural size. In any case, in order to back up the previous analyses based on SMI values, we also used crude body mass as a direct measure of body condition, as recommended by some previous studies (e.g. Schamber et al. 2009; Labocha and Hayes 2012).

\section{Models and hypotheses}

The initial step was the same for wing length, body mass and SMI: we tested for the relative influence of individual features and general environmental variation on these individual measurements. To do this, we took the value of these variables at recapture (i.e. the year following ringing) as the dependent variable, and tested the effect of these same variables at ringing, plus year and day of recapture, as predictors. General linear models with a normal distribution were used. Despite the fact that there could be uncorrected errors in bird measurements both at ringing and at recapture, we could not use an SMA regression here since we also wanted to simultaneously test for the effect of temporal covariates, and no such multivariate SMA software exists. Following Green et al. (2011), day of recapture was included as a second-order polynomial so as to allow for potential non-linear patterns of changes across the wintering season, e.g. the known seasonal changes in body condition over the winter, generally leading to body mass being maximum in mid-winter and minimum in early and late winter (Fox et al. 1992; Guillemain et al. 2005b). To reduce colinearity between day and day $^{2}$ (Legendre and Legendre 1998), 1 January was considered as day 0, days from August to December being considered as negative values. Non-significant terms were gradually removed until reaching a final model where all terms had a significant effect on wing length (backwards stepwise selection of the best GLM model, based on test statistics).

\section{Persistence of individual relative body condition}

The next analysis aimed at testing explicitly if the 'best' birds in terms of body condition are able to remain so over successive years. For this purpose, we computed for each individual its relative SMI score as the difference between its own SMI and the average SMI of all individuals of the same age and sex class the same year. This was done separately for the ringing and the recapture years and, since there was equivalent random and uncorrected error in both the $\mathrm{X}$ and the $\mathrm{Y}$ terms and no other covariates were considered, an SMA regression between the two scores was used to study their relationship with SMATR software. A significant positive correlation would indicate that some individuals have intrinsic features allowing them to repeatedly be the best birds of the population (in terms of body condition) year after year. A slope significantly greater than one would indicate that potential differences between individuals tend to increase over successive years. For a given sex and age class, only years in which 3 or more birds were ringed or recaptured were considered. The same procedure was repeated using relative body mass (compared to the mean value of the same sex and age class) at ringing and at recapture.

Body condition and recapture probability

The link between body condition and life history traits is beyond the scope of this study, and will be analysed elsewhere using capture-recapture models. Nevertheless, we here present a preliminary analysis of such potential links, 
comparing the mean SMI and body mass values between the birds recaptured the year after ringing (i.e. used in the present analysis, $n=634$ ) and those that were ringed at the same time but not recaptured or recovered dead the next year or following ones $(n=28817$, i.e. many of which are expected to have died; the annual survival of Teal has previously been estimated as $48.5 \%$ : Devineau et al. 2010). A GLM was used to compare mean SMI or mean body mass at capture between the two categories of birds (RECAPTURE), also considering the potential effects of year of ringing, day of ringing and day ${ }^{2}$ following the same procedures as above and SEXAGE (4 modalities: adult females, adult males, juvenile females and juvenile males). SMI of all birds were computed using the $b_{\text {SMA }}$ value computed above.

\section{Results}

\section{Wing length}

Wing length at recapture was mostly driven by wing length at ringing, and this was the only term remaining in the final model for juveniles and for adult females, while an additional effect of year of recapture was detected in adult males. Year of recapture, however, had a relatively minor effect in this category of birds, since it only contributed to $1.04 \%$ of the explained variance (ratio of partial $F$ values in Table 2). The final models provided fits to the data that ranged from $r^{2}=0.50$ to $r^{2}=0.69$.

\section{Body condition}

As for wing length, the main driver of SMI at recapture was SMI at ringing the previous year in all sex and age classes except adult females, where the final model only included a year effect but was not significant (Table 2). Year of recapture had an additive effect in all other cases, in addition to an effect of day of recapture in juvenile males, with the year effect contributing to $7.2-10.8 \%$ of the explained variance (based on ratios of partial $F$ values). In juvenile males, estimates for day and day ${ }^{2}$ were -0.023 $( \pm 0.101 \mathrm{SE})$ and -0.004 ( $\pm 0.002 \mathrm{SE})$, respectively, indicating a dome-shaped pattern with SMI at recapture being higher in mid- than in early or late winter in these birds. Day (as a second order polynomial) contributed to $13.35 \%$ of the explained variance in SMI at recapture for the juvenile males.

The analysis based on body mass instead of SMI yielded similar results, though this time the final model was also significant for adult females. Body mass at ringing was indeed the main determinant of body mass at recapture (fraction of explained variance contributed by body mass at ringing ranging from 68.4 to $91.2 \%$ ) though an effect of year in all sex and age classes but adult females, and an effect of day and day ${ }^{2}$ in females of both age classes were also detected (Table 2).

The final analyses indicated that the same individuals were repeatedly the 'best' of the population in terms of body condition: the slopes of the relationships between SMI scores (difference between the SMI of an individual and the mean SMI of conspecifics of the same sex and age class) over successive years were not significantly different from 1 (test of slope value: all $F<0.496$, all $P>0.485$ ), except in juvenile females where the slope was 1.158 , which was significantly different from $1(F=5.870$, $P=0.016)$ : Teal therefore retained their relative quality compared to conspecifics from year to year on average, except in juvenile females where birds in good relative condition at ringing tended to be even more so at recapture the following year (Fig. 1). When individual relative condition was inferred from relative body mass, individual relative quality at recapture was again proportional to individual relative quality at ringing, since the slope of the relationships between the two variables did not differ from 1 in any sex or age class (all $F<2.61$, all $P>0.108$; Fig. 2).

\section{Body condition and live recapture likelihood}

The GLM model to explain differences in mean SMI values was significant $\left(F_{18}, \quad 29,432=396.94, \quad r^{2}=0.20\right.$, $P<0.0001$ ), with all parameters but day having a significant effect: despite significant differences between sex and age classes, years and across days (significant effect of day $^{2}$ ), birds that were later recaptured had a significantly greater SMI value than birds that were not recaptured the year following the winter of ringing (RECAPTURE effect: partial $F$ value $=21.3, P<0.0001)$. The estimates in the GLM suggested that the mean SMI of birds that were recaptured was $3.56 \mathrm{~g}( \pm 0.77 \mathrm{SE})$ higher than that of birds which were not recaptured.

The result was the same when comparing crude body masses instead of SMI values: the same final GLM model was similarly significant $\left(F_{18,29,432}=474.68, r^{2}=0.22\right.$, $P<0.0001)$, and this time all parameters including day had a significant effect (RECAPTURE effect: partial $F$ value $=28.0, P<0.0001)$, and birds that were recaptured were $3.72 \mathrm{~g}( \pm 0.70 \mathrm{SE})$ heavier than those which were not recaptured.

\section{Discussion}

Teal showed high persistence in wing length and body condition from one year to the next, highlighting the major 
Table 2 Best models of the GLM testing the effect of wing length, scaled mass index (SMI, used as a measure of body condition) and body mass at ringing, year and day of recapture on wing length, SMI and body mass at recapture the following year

\begin{tabular}{|c|c|c|c|c|}
\hline & Estimate $\pm \mathrm{SE}$ & $d f$ & Partial $F$ & Partial $P$ value \\
\hline \multicolumn{5}{|l|}{ Adult females } \\
\hline \multicolumn{5}{|c|}{ Wing length at recapture (final model: $r^{2}=0.50 ; F_{1,52}=52.51 ; P<0.0001$ ) } \\
\hline Wing length at ringing & $0.71 \pm 0.1$ & 1 & 52.51 & $<0.0001$ \\
\hline \multicolumn{5}{|c|}{ SMI at recapture (final model: $r^{2}=0.26 ; F_{8,45}=2.02 ; P=0.0650$ ) } \\
\hline Year & & 8 & 2.02 & NS \\
\hline \multicolumn{5}{|c|}{ Body mass at recapture (final model: $r^{2}=0.21 ; F_{3,50}=4.45 ; P=0.0076$ ) } \\
\hline Body mass at ringing & $0.44 \pm 0.13$ & 1 & 11.18 & 0.0016 \\
\hline Day & $-0.13 \pm 0.14$ & 1 & 0.89 & NS \\
\hline Day $^{2}$ & $-0.01 \pm 0.00$ & 1 & 4.28 & 0.0438 \\
\hline \multicolumn{5}{|l|}{ Juvenile females } \\
\hline \multicolumn{5}{|c|}{ Wing length at recapture (final model: $r^{2}=0.57 ; F_{1,223}=313.82 ; P<0.0001$ ) } \\
\hline Wing length at ringing & $0.78 \pm 0.04$ & 1 & 313.82 & $<0.0001$ \\
\hline \multicolumn{5}{|c|}{ SMI at recapture (final model: $r^{2}=0.56 ; F_{10,224}=6.60 ; P<0.0001$ ) } \\
\hline Year & & 9 & 3.23 & 0.0010 \\
\hline SMI at ringing & $0.46 \pm 0.07$ & 1 & 41.88 & $<0.0001$ \\
\hline \multicolumn{5}{|c|}{ Body mass at recapture (final model: $r^{2}=0.16 ; F_{12,222}=3.57 ; P<0.0001$ ) } \\
\hline Year & & 9 & 1.98 & 0.0428 \\
\hline Body mass at ringing & $0.31 \pm 0.07$ & 1 & 19.55 & $<0.0001$ \\
\hline Day & $-0.01 \pm 0.07$ & 1 & 0.01 & NS \\
\hline Day $^{2}$ & $-0.01 \pm 0.00$ & 1 & 3.89 & 0.0497 \\
\hline \multicolumn{5}{|l|}{ Adult males } \\
\hline \multicolumn{5}{|c|}{ Wing Length at recapture (final model: $r^{2}=0.69 ; F_{13,157}=26.48 ; P<0.0001$ ) } \\
\hline Year & & 12 & 3.18 & 0.0004 \\
\hline Wing length at ringing & $0.77 \pm 0.04$ & 1 & 302.66 & $<0.0001$ \\
\hline \multicolumn{5}{|c|}{ SMI at recapture (final model: $r^{2}=0.42 ; F_{13,157}=8.79 ; P<0.0001$ ) } \\
\hline Year & & 12 & 4.50 & $<0.0001$ \\
\hline SMI at ringing & $0.44 \pm 0.07$ & 1 & 37.31 & $<0.0001$ \\
\hline \multicolumn{5}{|c|}{ Body mass at recapture (final model: $r^{2}=0.35 ; F_{13,157}=7.90 ; P<0.0001$ ) } \\
\hline Year & & 12 & 4.04 & $<0.0001$ \\
\hline Body mass at ringing & $0.45 \pm 0.07$ & 1 & 42.15 & $<0.0001$ \\
\hline \multicolumn{5}{|l|}{ Juvenile males } \\
\hline \multicolumn{5}{|c|}{ Wing length at recapture (final model: $r^{2}=0.57 ; F_{1,172}=229.87 ; P<0.0001$ ) } \\
\hline Wing length at ringing & $0.69 \pm 0.05$ & 1 & 229.87 & $<0.0001$ \\
\hline \multicolumn{5}{|c|}{ SMI at recapture (final model: $r^{2}=0.28 ; F_{13,160}=6.29 ; P<0.0001$ ) } \\
\hline Year & & 10 & 2.97 & 0.0018 \\
\hline SMI at ringing & $0.38 \pm 0.07$ & 1 & 29.60 & $<0.0001$ \\
\hline Day & $-0.02 \pm 0.10$ & 1 & 0.05 & 0.8182 \\
\hline Day $^{2}$ & $-0.004 \pm 0.00$ & 1 & 4.97 & 0.0272 \\
\hline \multicolumn{5}{|c|}{ Body mass at recapture (final model: $r^{2}=0.27 ; F_{11,162}=5.49 ; P<0.0001$ ) } \\
\hline Year & & 10 & 3.25 & 0.0007 \\
\hline Body mass at ringing & $0.32 \pm 0.07$ & 1 & 21.77 & $<0.0001$ \\
\hline
\end{tabular}

Only the final models are presented (see text). For continuous independent variables, the value of estimate \pm SE is given

role played by the intrinsic features of each individual (likely having a genetic basis or being acquired during early development and growth of the individual) on variation in such measurements, in addition to inter and intraannual environmental factors.
Wing length

Individual wing length was very stable from one year to the next in adult birds. Although they are known to affect wing feather growth (e.g. Hall and Fransson 2000; Lyons 

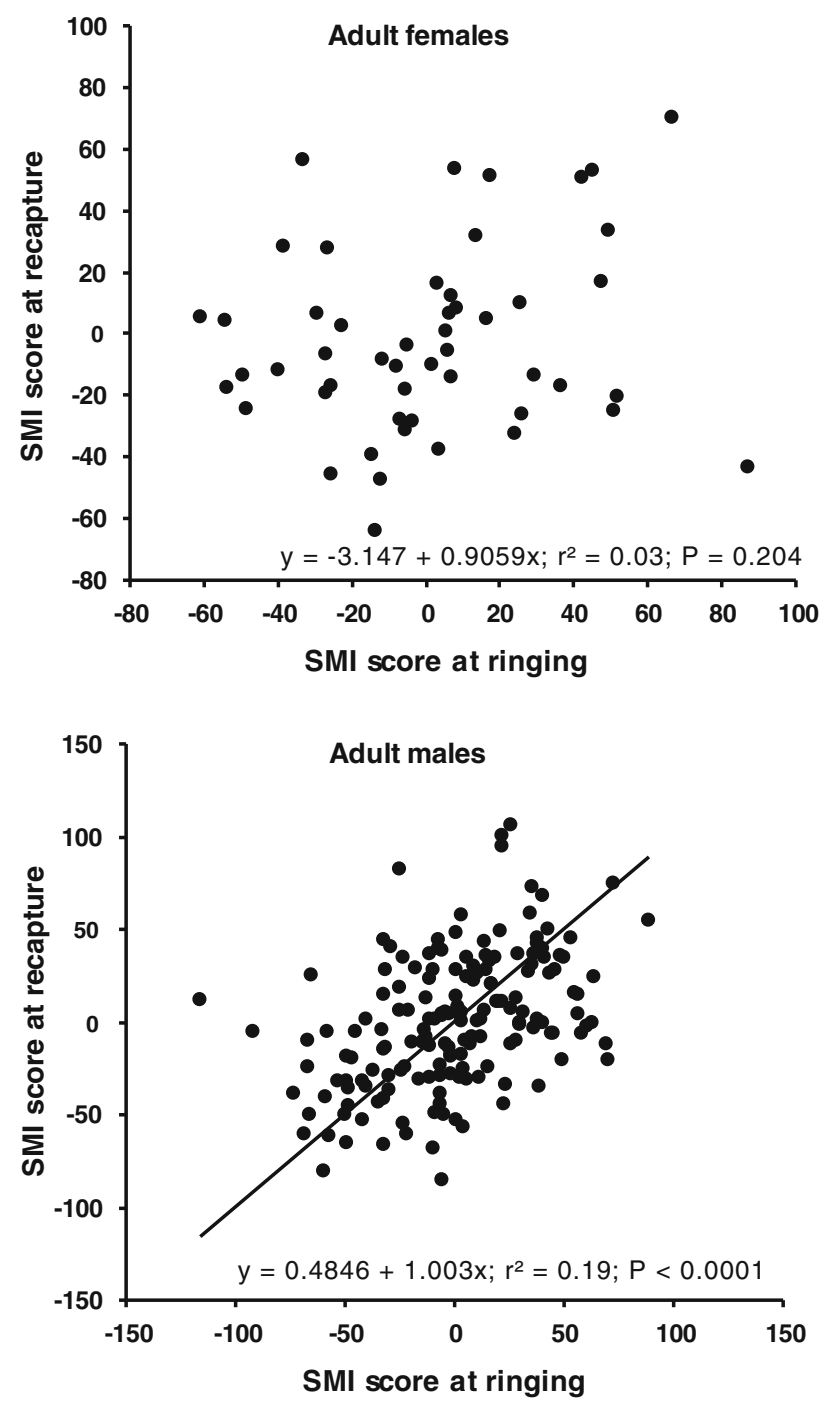

Fig. 1 Relationships between relative SMI (scaled mass index, used as a measure of body condition) scores at ringing and relative SMI scores of Teal Anas crecca at recapture in each sex and age class. Individual SMI scores were standardized by subtracting the mean

and Roby 2011), environmental conditions (here considered under the integrative year effect) apparently had a relatively limited effect on Teal wing length compared to intrinsic features of each individual (see also De la Hera et al. 2009). This may partly be due to the fact that wing length not only depends on primary feather length, which may be affected by environmental conditions during annual moult, but also on the length of underlying wing bones (humerus, radius, ulna and manus; Nudds et al. 2011). Such bones do not vary in length once adult age is reached, and are unlikely to grow much even between juvenile and adult ages: indeed, measurement of tarsus length in over 7,500 Teal showed no significant skeletal growth between firstyear and adult females, and a marginal $0.2 \mathrm{~mm}$ difference in males (M. Guillemain et al., unpublished data). The present results therefore support previous studies
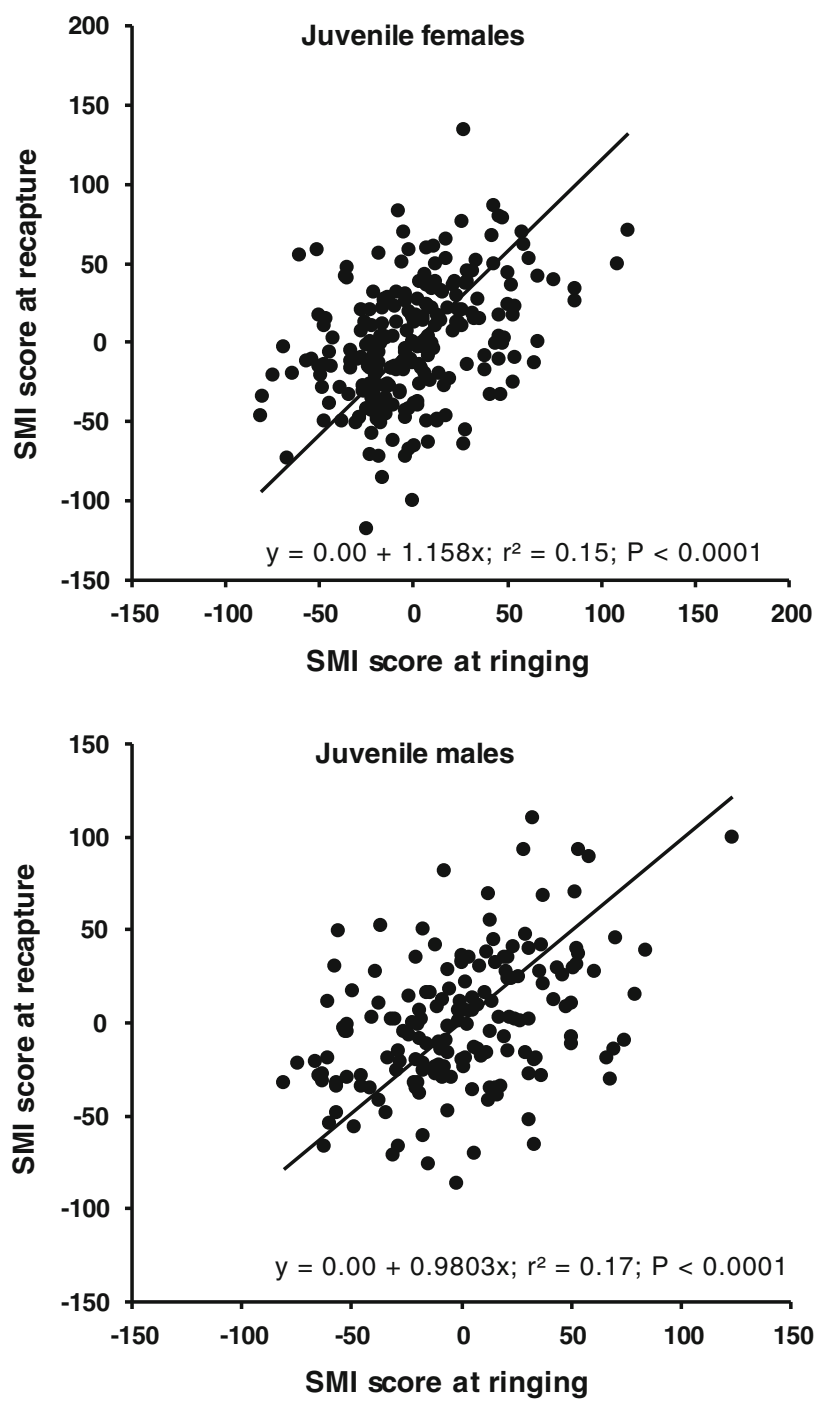

values for that age and sex class in the same year (see "Methods"). Note that many dots are superimposed. The fitted line and statistics are those of standard major axis regressions

suggesting that wing length has a strong genetic basis in birds (e.g. Berthold and Querner 1982; Christe et al. 2000). Although the use of wing length alone may not be enough to provide the best measure of individual structural size (Freeman and Jackson 1990; Wishart 1979), the present results at least suggest that in Teal wing length shows strong persistence from year to year for each individual.

Body condition

Not surprisingly, environmental variation (measured through the year effect) affected the body condition index (SMI) more than it affected wing length: we found evidence of a year effect on body condition in males of both age classes and in juvenile females, which contributed to $7-11 \%$ of the explained variance (ratios of partial 

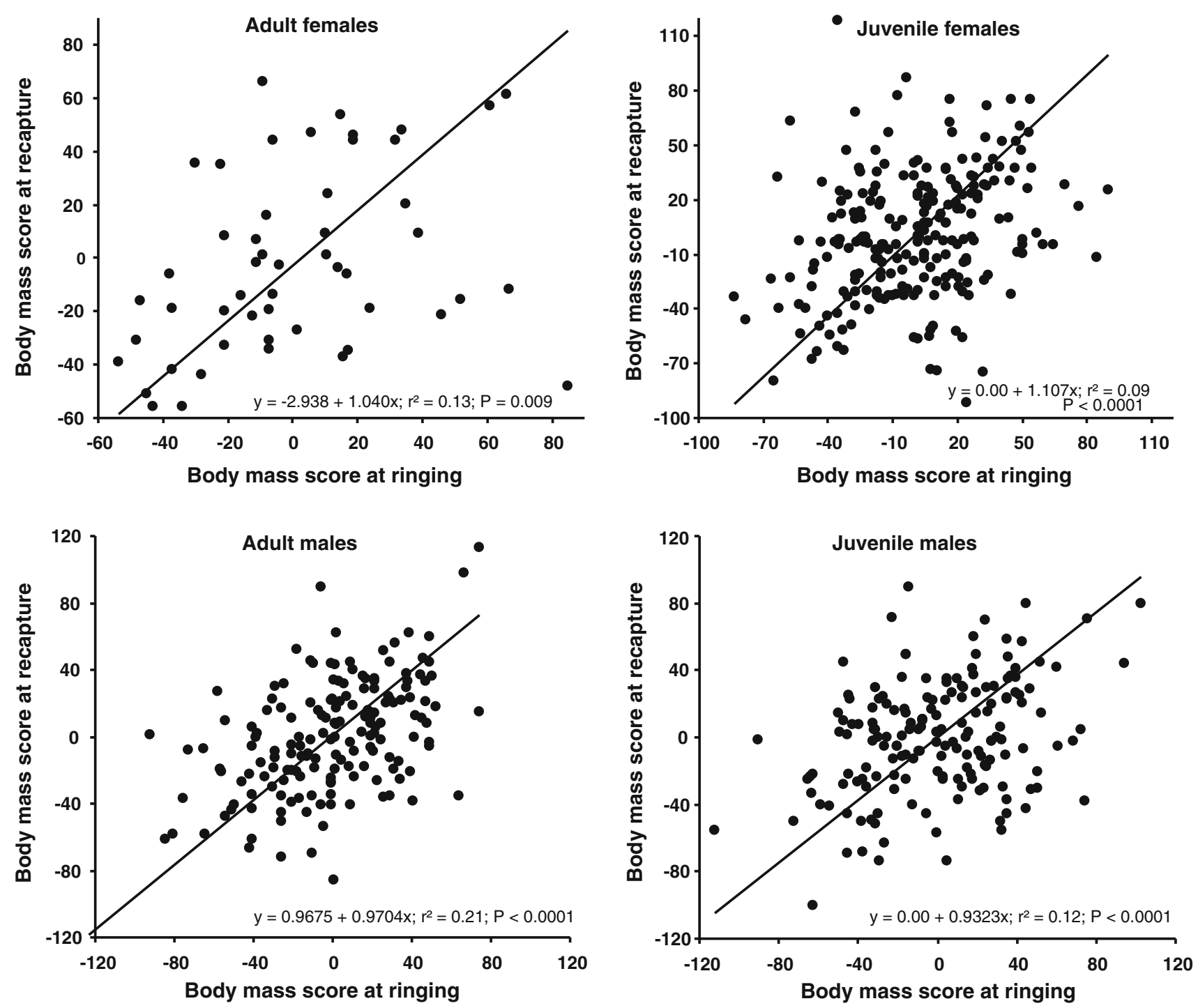

Fig. 2 Relationships between relative body mass (used as an alternative measure of body condition) scores at ringing and relative body mass scores at recapture in each sex and age class. Individual body mass scores were standardized by subtracting the mean values

$F$ values). The lack of significance of the final model for adult females may likely be due to the small sample size (54 birds) scattered over 16 years (1956-1972). In juvenile males, SMI was also affected by environmental change over time, since day of recapture (included as a second order polynomial effect) contributed to ca. one-sixth of the explained variance. The reason why juvenile males were more affected by intra-annual (i.e. seasonal) environmental changes, while the other sex and age classes responded more to inter-annual changes, remains unclear. However, that environmental factors strongly affect duck body condition is not a new finding; as in most migratory birds, migration events are associated with body mass and body composition changes (e.g. Clark 1979; McLandress and Raveling 1981; Ebbinge and Spaans 1995) and, even

for that age and sex class in the same year (see "Methods"). Note that many dots are superimposed. The fitted line and statistics are those of standard major axis regressions

within the winter season, duck body condition is known to vary strongly because of changes in behaviour, especially the need to spend extended periods of time in courtship display to form pairs (Baldassarre et al. 1986; Fox et al. 1992; Tamisier et al. 1995; Guillemain et al. 2005b; Rhodes et al. 2006; Moon and Haukos 2009). Ducks are particularly sensitive to changes in environmental conditions such as weather fluctuations (Lebreton 1973; Ridgill and Fox 1990), which likely explain the inter-annual variations in body condition recorded here. Body condition indices are also subjected to significant annual variation in other migratory birds (Amat et al. 2001; Norte et al. 2009).

Using crude body mass as an index of body condition provided globally similar results to those using SMI. The final models, however, provided a slightly poorer fit to the 
data (lower $r^{2}$ values; Table 2), and body mass at ringing contributed a somewhat smaller proportion of the explained variance. This seems likely to be because this variable includes no correction for structural size, and is therefore a combined measure of size and condition (Peig and Green 2009, 2010). Nevertheless, these analyses are consistent with those of SMI and further suggest that body condition at recapture was related to body condition at ringing.

Although bird body condition is regularly measured and correlated to life-history traits during the breeding season, this is to our knowledge the first study addressing and demonstrating persistence of winter body condition between successive years in ducks. The causes of variation in wintering Teal individual quality are unknown but likely to include genetic variation, the consequences of fledging earlier (e.g. Blums et al. 2002 found greater recruitment of ducklings hatched earlier), long-term effects of exposure to heavy metals or other contaminants (Guillemain et al. 2007a), parasite loads (Green et al. 2011), differential use of the wintering habitat (Guillemain et al. 2007b), etc.

Various different measures of body condition are considered as proxies for individual fitness (Stevenson and Woods 2006), and the SMI performs better than alternative indices based on body mass and length (Peig and Green 2010; Bókony et al. 2012). There is evidence that such indices are related to survival rates in ducks, e.g. lead poisoning reduces both (Mateo et al. 1998; Guillemain et al. 2007a). As a preliminary analysis, we compared the mean SMI values and crude body weights between the birds recaptured the year after ringing and those that were ringed at the same time but not recaptured the following year: even after controlling for year, day and $\mathrm{day}^{2}$ and differences between sex and age classes, birds that got recaptured the following year indeed had a greater SMI value and a heavier weight on average than those that were not. Though not a formal demonstration of the consequences of winter body condition for future survival, which will require more in-depth capture-recapture modelling, this suggests that better body condition leads to greater probability of recapture at the same spot the next year (i.e. likely greater survival) in Teal. Admittedly, this may also indicate that our other analyses only highlighted body condition changes in "high quality" birds, which were more likely to be recaptured and hence weighed and measured twice.

If body condition is indeed positively related to individual fitness in ducks (e.g. Johnson et al. 1992; Blums et al. 2005), then our results support the hypothesis that some individuals repeatedly produce more offspring and/or survive better over successive seasons, at least for males and juvenile females. It has recently been suggested that the sustainability of European Common Teal populations is mainly possible because of inter-individual demographic heterogeneity, with a limited proportion of the individuals contributing to most of the population recruitment (Devineau 2007). The present results are also in accordance with such "structured" or "fixed" heterogeneity (e.g. Kendall and Fox 2003; as opposed to "dynamic heterogeneity" in Tuljapurkar et al. 2009), also termed "static traits" of individuals in the population (review in Bergeron et al. 2011), since the 'best' birds here seem to repeatedly be the same individuals over successive winters, and an earlier analysis of the same dataset suggested a link (though indirect) between late winter body condition of Teal and their subsequent breeding success (Guillemain et al. 2008). Our slope analyses of the regression between body condition in successive years indeed indicates that the difference in body condition between individuals remains stable over time for males, with no evidence that individuals in poor condition catch up with those in better condition. Furthermore, in juvenile females, the slope was greater than 1 , indicating that, on average, the difference between better and poorer individuals tends to increase over time. This positive reinforcement of early condition advantage for females might be because juveniles in better condition breed earlier in their first year, and this may give them a critical advantage in recovering condition before the following winter. Similarly, Kittiwakes Rissa tridactyla with a higher SMI lay eggs earlier in the season (Goutte et al. 2010). On the other hand, we found no correlation between years for SMI in adult females (although we did for body mass). This might be explained by the smaller sample size, but this seems unlikely given the radical differences in $r^{2}$ values in Fig. 2. Alternatively, it may indicate a genuine difference between sexes in adults in this relatively $r$-selected species. Females may potentially make such a high reproductive investment in their second or later reproductive years that they lose any advantage in body condition from one winter to the next.

Our findings lend further support to the value of the SMI as a condition index (see also Peig and Green 2010; Bókony et al. 2012; Champagnon et al. 2012), and the relationship between SMI at ringing and at recapture was tighter than when relating crude body mass measurements. Future work relating the changes in individual body condition over time to reproductive success and survival in ducks, as well as in a range of other species, is highly desirable to allow us to better understand the relationships between body condition and individual fitness. Future research is also required into the sex and age differences in the persistence of winter body condition over time in Teal and other species, as well as their potential causes. Being able to simultaneously assess inter-individual differences in condition and fitness via the use of such simple indices 
will also help the understanding of how individual heterogeneity contributes to population sustainability.

Acknowledgments We are grateful to Luc Hoffmann, Hubert Kowalski, Heinz Hafner, Alan Johnson and others who ringed Teal at the Tour du Valat over 25 years. Marc Lutz, Paul Isenmann and the Centre de Recherche sur la Biologie des Populations d'Oiseaux (Muséum National d'Histoire Naturelle, Paris) helped to computerize the ringing database. We thank Jeffrey M. Black, Eileen Rees, Olivier Chastel and three referees for useful advice, and the MAVA Foundation for financial support.

\section{Appendix}

Details of SMI calculations: $\mathrm{L}_{0}$ is the mean wing length at ringing per sex and age class, used in equation $S M I_{i}=$ $M_{i}\left[\frac{L_{0}}{L_{i}}\right]^{b_{S M A}}$, where $\mathrm{SMI}_{i}$ is the scaled mass index of individual $i, \mathrm{M}_{i}$ is the body mass of individual $i, \mathrm{~L}_{0}$ is the mean wing length of individuals of the same sex and age category as individual $i, \mathrm{~L}_{i}$ is the wing length of individual $i$ and $b_{\mathrm{SMA}}$ is the slope of the standard major axis regression of body mass on wing length, both ln-transformed (see Peig and Green 2009: fig. 1 for details). $\mathrm{L}_{0}$ and SMI are also provided for measurements performed at recapture. The slope and $r^{2}$ value of the standard major axis regression of $\operatorname{Ln}\left(\mathrm{M}_{i}\right)$ on $\mathrm{Ln}\left(\mathrm{L}_{i}\right)$ were $b_{\mathrm{SMA}}=4.005(95 \%$ confidence interval 3.754-4.272), and $r^{2}=0.315$ $(P<0.0001$; see main text $)$, respectively.

\begin{tabular}{llllll}
\hline & \multicolumn{2}{l}{ Ringing } & & & \multicolumn{2}{l}{ Recapture } \\
\cline { 2 - 3 } \cline { 6 - 7 } \cline { 6 - 7 } & $\mathrm{L}_{0}$ & Mean SMI & & $\mathrm{L}_{0}$ & Mean SMI \\
\hline Adult males & 190.91 & 342.70 & & 191.79 & 344.12 \\
Adult females & 183.22 & 316.47 & & 183.94 & 301.93 \\
Juvenile males & 188.27 & 330.33 & & 190.83 & 341.40 \\
Juvenile females & 181.01 & 297.45 & & 183.09 & 302.82 \\
\hline
\end{tabular}

\section{References}

Alisauskas RT, Ankney CD (1992) The cost of egg laying and its relationship to nutrient reserves in waterfowl. In: Batt BDJ, Afton AD, Anderson MG, Ankney CD, Johnson DH, Kadlec JA, Krapu GL (eds) Ecology and management of breeding waterfowl. University of Minnesota Press, Minneapolis, pp 30-61

Amat JA, Fraga RM, Arroyo GM (2001) Variations in body condition and egg characteristics of female kentish plovers Charadruis alexanderinus. Ardea 89:293-299

Ankney CD, MacInness CD (1978) Nutrient reserves and reproductive performance of female Lesser Snow Geese. Auk 95: 459-471

Anteau MJ, Afton AD (2009) Lipid reserves of Lesser Scaup (Aythya affinis) migrating across a large landscape are consistent with the "spring condition" hypothesis. Auk 126:873-883
Arnold TW, Green AJ (2007) On the allometric relationship between size and composition of avian eggs: a reassessment. Condor 109:705-714

Baldassarre GA, Whyte RJ, Bolen EG (1986) Body weight and carcass composition of nonbreeding Green-winged Teal on the Southern high plains of Texas. J Wildl Manag 50:420-426

Barbraud C, Weimerskirch H (2005) Environmental conditions and breeding experience affect costs of reproduction in Blue Petrels. Ecology 86:682-692

Bergeron P, Baeta R, Pelletier F, Réale D, Garant D (2011) Individual quality: tautology or biological reality? J Anim Ecol 80:361-364

Berthold P, Querner U (1982) Genetic basis of moult, wing length, and body weight in a migratory species, Sylvia atricapilla. Experientia 38:801-802

Black JM, Prop J, Larsson K (2007) Wild goose dilemmas. Branta, Groningen

Blas J, Sergio F, Hiraldo F (2009) Age-related improvement in reproductive performance in a long-lived raptor: a crosssectional and longitudinal study. Ecography 32:647-657

Blums P, Clark RG (2004) Correlates of lifetime reproductive success in three species of European ducks. Oecologia 140:61-67

Blums P, Clark RG, Mednis A (2002) Patterns of reproductive effort and success in birds: path analyses of long-term data from European ducks. J Anim Ecol 71:280-295

Blums P, Nichols JD, Hines JE, Lindberg MS, Mednis A (2005) Individual quality, survival variation and patterns of phenotypic selection on body condition and timing of nesting in birds. Oecologia 143:365-376

Bókony V, Seress G, Nagy S, Lendvai AZ, Liker A (2012) Multiple indices of body condition reveal no negative effect of urbanization in adult house sparrows. Landsc Urban Plan 104:75-84

Bowler JM (1996) Feeding strategies of Bewick's Swans (Cygnus columbianus columbianus) in winter. $\mathrm{PhD}$ thesis, University of Bristol

Cam E, Gimenez O, Alpizar-Jara R, Aubry LM, Authier M, Cooch EG, Koons DN, Link WA, Monnat JY, Nichols JD, Rotella JL, Royle JA, Pradel R (2013) Looking for a needle in a haystack: inference about individual fitness components in a heterogeneous population. Oikos, in press

Catry P, Ruxton GD, Ratcliffe N, Hamer KC, Furness RW (1999) Short-lived repeatabilities in long-lived great skuas: implications for the study of individual quality. Oikos 84:473-479

Champagnon J, Guillemain M, Elmberg J, Massez G, Cavallo F, Gauthier-Clerc M (2012) Low survival after release into the wild: assessing "the burden of captivity" on Mallard physiology and behaviour. Eur J Wildl Res 58:255-267

Chastel O, Weimerskirch H, Jouventin P (1995) Body condition and seabird reproductive performance. A case study of three Petrel species. Ecology 76:2240-2246

Christe P, Møller AP, Saino N, De Lope F (2000) Genetic and environmental components of phenotypic variation in immune response and body size of a colonial bird, Dellichon urbica (the house martin). Heredity 85:75-83

Clark GA Jr (1979) Body weights of birds: a review. Condor 81:193-202

Conroy MJ, Costanzo GR, Stotts DB (1989) Winter survival of female American Black Ducks on the Atlantic Coast. J Wildl Manag 53:99-109

Davis BE, Afton AD, Cox RR (2011) Factors affecting winter survival of female mallards in the lower Mississippi alluvial valley. Waterbirds 34:186-194

De la Hera I, Pérez-Tris J, Telleria JL (2009) Repeatable length and mass but not growth rate of individual feathers between moults in a passerine bird. Acta Ornithol 44:95-99 
Devineau O (2007) Dynamique et gestion des populations exploitées: l'exemple de la sarcelle d'hiver. PhD thesis, Université Montpellier II, France

Devineau O, Guillemain M, Johnson AR, Lebreton JD (2010) A comparison of green-winged teal Anas crecca survival and harvest between Europe and North America. Wildl Biol $16: 12-24$

Ebbinge BS, Spaans B (1995) The importance of body reserves accumulated in spring staging areas in the temperate zone for breeding in Dark-bellied Brent Geese Branta $b$. bernicla in the high Arctic. J Avian Biol 26:105-113

Evans ME (1979) Aspects of the life cycle of the Bewick's Swan, based on recognition of individuals at a wintering site. Bird Study 26:149-162

Flinks H, Salewski V (2012) Quantifying the effect of feather abrasion on wing and tail lengths measurements. J Ornithol 153:1053-1065

Fox AD, King R, Watkin J (1992) Seasonal variation in weight, body measurements and condition of free-living Teal. Bird Study 39:53-62

Freeman S, Jackson WM (1990) Univariate metrics are not adequate to measure avian body size. Auk 107:69-74

Gimenez O, Choquet R (2010) Individual heterogeneity in studies on marked animals using numerical integration: capture-recapture mixed models. Ecology 91:951-957

Gladbach A, Gladbach DJ, Quillfeldt P (2010) Seasonal clutch size decline and individual variation in the timing of breeding are related to female body condition in a non-migratory species, the Upland Goose Chloephaga picta leucoptera. J Ornithol 151:817-825

Goutte A, Angelier F, Chastel CC, Trouve C, Moe B, Bech C, Gabrielsen GW, Chastel O (2010) Stress and the timing of breeding: glucocorticoid-luteinizing hormones relationships in an arctic seabird. Gen Comp Endocrinol 169:108-116

Green AJ (2001) Mass/length residuals: measures of body condition or generators of spurious results? Ecology 82:1473-1483

Green AJ, Figuerola J, King R (2001) Comparing evolutionary and static allometry in the Anatidae. J Ornithol 142:321-334

Green AJ, Georgiev BB, Brochet AL, Gauthier-Clerc M, Fritz H, Guillemain M (2011) Determinants of the prevalence of the cloacal cestode Cloacotaenia megalops in teal wintering in the French Camargue. Eur J Wildl Res 57:275-281

Guillemain M, Mondain-Monval JY, Johnson AR, Simon G (2005a) Long-term climatic trend and body size variation in Teal (Anas crecca). Wildl Biol 11:81-88

Guillemain M, Dehorter O, Johnson AR, Simon G (2005b) A test of the wintering strategy hypothesis with teal (Anas crecca) ringed in the Camargue, southern France. J Ornithol 146:184-187

Guillemain M, Devineau O, Lebreton JD, Mondain-Monval JY, Johnson AR, Simon G (2007a) Lead shot and teal (Anas crecca) in the Camargue, Southern France: effects of embedded and ingested pellets on survival. Biol Conserv 137:567-576

Guillemain M, Fritz H, Johnson AR, Simon G (2007b) What type of lean ducks do hunters kill? Weakest local ones rather than migrants. Wildl Biol 13:102-107

Guillemain M, Elmberg J, Arzel C, Johnson AR, Simon G (2008) The income-capital breeding dichotomy revisited: late winter body condition is related to breeding success in an income breeder. Ibis $150: 172-176$

Guillemain M, Hearn R, King R, Gauthier-Clerc M, Simon G, Caizergues A (2009) Differential migration of the sexes cannot be explained by the body size hypothesis in Teal. J Ornithol 150:685-689

Hall KSS, Fransson T (2000) Lesser Whitethroats under timeconstraint moult more rapidly and grow shorter wing feathers. J Avian Biol 31:583-587
Haramis GM, Nichols JD, Pollock KH, Hines JE (1986) The relationship between body mass and survival of wintering Canvasbacks. Auk 103:506-514

Hatch MI, Smith RJ (2010) Repeatability of hematocrits and body mass of Gray Catbirds. J Field Ornithol 81:64-70

Hauser CE, Cooch EG, Lebreton JD (2006) Control of structured populations by harvest. Ecol Mod 196:462-470

Hepp GR, Kennamer RA (1993) Effects of age and experience on reproductive performance of wood ducks. Ecology 74:20272036

Hohman WL (1993) Body composition of wintering canvasbacks in Louisiana: dominance and survival implications. Condor 95:377-387

Johnson DH, Nichols JD, Schwartz MD (1992) Population dynamics of breeding waterfowl. In: Batt BDJ, Afton AD, Anderson MG, Ankney CD, Johnson DH, Kadlec JA, Krapu GL (eds) Ecology and management of breeding waterfowl. University of Minnesota Press, Minneapolis, pp 446-485

Kendall BE, Fox GA (2002) Variation among individuals and reduced demographic stochasticity. Conserv Biol 16:109-116

Kendall BE, Fox GA (2003) Unstructured individual variation and demographic stochasticity. Conserv Biol 17:1170-1172

Krapu GL (1981) The role of nutrient reserves in Mallard reproduction. Auk 98:29-38

Labocha MK, Hayes JP (2012) Morphometric indices of body condition in birds: a review. J Ornithol 153:1-22

Lebreton JD (1973) Etude des déplacements saisonniers des sarcelles d'hiver, Anas c. crecca L., hivernant en Camargue à l'aide de l'analyse factorielle des correspondances. CR Acad Sci D 277:2417-2420

Legendre P, Legendre L (1998) Numerical ecology. Elsevier, Amsterdam

Lindén M, Gustafsson L, Part T (1992) Selection on fledging mass in the Collared Flycatcher and the Great Tit. Ecology 73:336-343

Lyons DE, Roby DD (2011) Validating growth and development of a seabird as an indicator of food availability: captive-reared Caspian Tern chicks fed ad libitum and restricted diets. J Field Ornithol 82:88-100

Madsen T, Shine R (1999) The adjustment of reproductive threshold to prey abundance in a capital breeder. J Anim Ecol 68: $571-580$

Mateo R, Belliure J, Dolz JC, Aguilar Serrano JM, Guitart R (1998) High prevalences of lead poisoning in wintering waterfowl in Spain. Arch Environ Contam Toxicol 35:342-347

McLandress MR, Raveling DG (1981) Changes in diet and body composition of Canada geese before spring migration. Auk 98:65-79

Milonoff M, Pöysä H, Runko P (2002) Reproductive performance of Common Goldeneye Bucephala clangula females in relation to age and lifespan. Ibis 144:585-592

Moon JA, Haukos DA (2009) Factors affecting body condition of Northern Pintails wintering in the Playa Lakes region. Waterbirds 32:87-95

Norte AC, Ramos JA, Sousa JP, Sheldon BC (2009) Variation of adult Great Tit Parus major body condition and blood parameters in relation to sex, age, year and season. J Ornithol 150:651-660

Nudds RL, Kaiser GW, Dyke GJ (2011) Scaling of avian primary feather length. PLoS ONE 6:e15665

Nur N (1984) The consequences of brood size for breeding Blue Tits I. Adult survival, weight change and the cost of reproduction. J Anim Ecol 53:479-496

O’Hara PD, Fernández G, Haase B, De la Cueva H, Lank DB (2006) Differential migration in western sandpipers with respect to body size and wing length. Condor 108:225-232

Ormerod SJ, Tyler SJ (1990) Assessments of body condition in Dippers Cinclus cinclus: potential pitfalls in the derivation and 
use of condition indices based on body proportions. Ring Migr 11:31-41

Peig J, Green AJ (2009) New perspectives for estimating body condition from mass/length data: the scaled mass index as an alternative method. Oikos 118:1883-1891

Peig J, Green AJ (2010) The paradigm of body condition: a critical reappraisal of current methods based on mass and length. Funct Ecol 24:1323-1332

Raveling DG (1981) Survival, experience, and age in relation to breeding success of Canada geese. J Wildl Manag 45:817-829

Rhodes OEJr, DeVault TL, Smith LM (2006) Seasonal variation in carcass composition of American Wigeon wintering in the Southern High Plains. J Field Ornithol 77:220-228

Ridgill SC, Fox AD (1990) Cold weather movements of waterfowl in Western Europe. International Waterfowl Research Bureau Special publication 13. IWRB, Slimbridge, UK

Rising JD, Somers KM (1989) The measurement of overall body size in birds. Auk 106:666-674

Robert A, Couvet D, Sarrazin F (2002) Fitness heterogeneity and viability of restored populations. Anim Conserv 5:153-161
Robert A, Sarrazin F, Couvet D (2003) Variation among individuals, demographic stochasticity, and extinction: response to Kendall and Fox. Conserv Biol 17:1166-1169

Schamber JL, Esler D, Flint PL (2009) Evaluating the validity of using unverified indices of body condition. J Avian Biol 40:49-56

Stevenson RD, Woods WA (2006) Condition indices for conservation: new uses for evolving tools. Int Comp Biol 46:1169-1190

Tamisier A, Allouche L, Aubry F, Dehorter O (1995) Wintering strategies and breeding success: hypothesis for a trade-off in some waterfowl species. Wildfowl 46:76-88

Tuljapurkar S, Steiner UK, Orzack SH (2009) Dynamic heterogeneity in life histories. Ecol Lett 12:93-106

Voelker G (2001) Morphological correlates of migratory distance and flight display in the avian genus Anthus. Biol J Linn Soc 73:425-435

Warton DI, Wright IJ, Falster DS, Westoby M (2006) Bivariate linefitting methods for allometry. Biol Rev 81:259-291

Wishart RA (1979) Indices of structural size and condition of American Wigeon (Anas americana). Can J Zool 57:2369-2374 